\title{
STATE, TRENDS AND PERSPECTIVES FOR THE DEVELOPMENT OF EXTREME TOURISM IN BULGARIA (PRESENTING THE CASE OF THE OFF-ROAD "BULGARIA TROPHY CHALLENGE 2017")
}

\author{
V. Zheleva* \\ Department of Regional Development, Faculty of Economics, TrakiaUniversity, \\ Stara Zagora, Bulgaria
}

\begin{abstract}
The intenselife style at the beginning of the $21^{\text {st }}$ century implies a development of new alternative forms of tourism, related to relaxation, maintenance of good health and recovery of physical and mental balance. Seekers of strong sensations are usually active consumers of specific tourist services, and this is why the extreme forms of tourism are dynamically introduced and offered on the Bulgarian tourist market. The aim of this research is to study the attitudes among participants and observers of one of the most extreme sports in Bulgaria- the off-road. There search aims to show how the conditions of the events satisfy tourists, what their preferences are to improve and diversify their vacation. There search methods used are the following: statistical, historical, comparative analysis, regional analysis, survey. The assessment of this type of tourism is rather positive and based generally on the possibility of combining active recreation with sports, where there are strong sensations and high adrenaline; the possibility of combining extreme forms of tourism with the so called event tourism, which allows the participants to be involved in a particular community; going beyond the traditional everyday life, based on a strongly urbanized lifestyle with high levels of stress and tension.
\end{abstract}

Key words: tourism, extreme tourism, extreme sports, off-road competitions

\section{INTRODUCTION}

The modern passive lifestyle presupposes the development of new alternative forms of tourism related to the combination of actives port and relaxation, on the basis of which good health are maintained and physical and mental balance forces are restored. The second decade of the $21^{\text {st }}$ century witnesses the active introduction on the Bulgarian tourist market of specific tourist services aimed at those who are looking for strong sensations, and who are active users of extreme forms of tourism. Modern sports and recreational tourism are more widespread among highly industrialized developing countries.These kinds of sport grow at a high rate and become a leading sector of global tourism. It is already wellknown that at the beginning of the century new forms of alternative tourism are being launched so that they could be associated with active recreation and maintain high levels of vitality. Their fast (fast-paced) penetration and the implementation on the Bulgarian tourist

\footnotetext{
*Correspondence to:Violetka Zheleva, Department ofRegional Development, Faculty ofEconomics, TrakiaUniversity,StaraZagora 6000, Bulgaria, email:vili_vili_88@abv.bg
}

market is mostly related to popular extreme sports.

Extreme forms of tourism can be viewed primarily as air, water and land travel. Among those taking place onshore, off-road tourism is among the most popular. Off-road or offroading is a term used as a type of entertainment that has become a motor- a sport that drives off-road vehicles on difficult terrain - dirt roads or trails, sand, gravel, river beds, mud, snow, rocks and other natural terrain. (1) In the public space, it is already recognized that off-road is a mixture of sports and entertainment. It is widely accepted that driving on extreme terrain is often fun and, in recent years, has become a popular recreation and sport for off-roaders, powered by two or four-wheel drive and motorcycles. The vehicles have been divided in many different categories, depending on the experience of drivers and the type of technique. In sports history, a new wave of "extreme sports" have found their proper niche. They combine sports with increased risk, non-standard thinking and behavior. A large part of this group of sports have existed since ancient times in the form of an ancient initiation ritual or a local tradition 
aiming to be an exhibit of courage and fearlessness. (2)

Off-road competitions began to be practiced first in Iceland in the 1980s, and since then they have spread widely in Scandinavia. Competitions are often held in sandy and gravel-covered quarries where the routes are shaped and often involve climbing verticals lopes. Vehicles use tires whose grapples are shaped as shovels. For a long time in Bulgaria there has been no comprehensive in form ative site for supporters and competitors with $4 \times 4$ cars. Following the fast development of this sport and the boom in SUV sales, here comes the moment when off-road starts to become professional and the requirements for the entrants and enthusiasts are rising. Even though this sport is quite new in Bulgaria (it was introduced in the summer of 1999), the contestants and organizers have proven that their practice does not differ much from the countries with more extensive experience.. The competitions in Bulgaria are some of the toughest so far, and the number of prizes of our athletes abroads how that we are as professional as they are. Bulgarians have won races in Macedonia, Romania, Germany, and this year we have a strong participation in international off-road events. (3)

The birthday of organized off-road competitions is considered the summer of 1999 when a group of enthusiasts gathered at Passarella to check the capabilities of their $4 \times 4$ cars. The doyenes are Zlatko Milev, Svetoslav Doychinov, Plamen Yotsov, Petar Tsikalov, the Antov's brothers and others. Subsequently, the first off-road club "Ancient Rome Roads" was registered with Dr. S. Doychinov. But, as always, a competitive fraction emerged as their rivals from "4x4 EXTREME" club joined the race and the development of the sport became a fury In 2001, "Ancient Roman Roads" organized the first official competition, where over 30 crews from Bulgaria and one from Macedonia gathered in Kremikovtzi. Immediately "4x4 EXTREME" organized the first competition for navigation notes "Shumen 2001", gathering more than 30 crews, 7 of which came from Romania. The next year in Bulgaria there was already a National Championship and for the first time a Bulgarian off-road champion was selected. From the non, the sport has been developing fast and the Championships have become more organized and the players more and more professional. (4)
Other clubs in Bulgaria include ASA "Geo offroad 4x4", city of Burgas, ASC "Off-road Club Varna", ASC "Black Sea Off-road Club" Varna, ASK "4x4 Adventure" Association, 4x4 Sofia ASK "4x4 Karlovo "ASR" Brutal racing", ASC" Gladiator Sporting Off-road Club "," Sofia off-road racing "ASK," Hot Extreme SBK ", ASK" 4x4 Shumen ".

One of the first is the Varna Off-Road Club, file no. 1049/2006 and decision №2009 / 2006. The founders are the most enthusiastic supporters of the off-road in the city. The goal of the clubis to develop the off-road races as a sport and as an alternative way to recreation. Off-road Club Varna is the organizer of the third traditional off-road tournament "VARNA TROPHY - 2006" 3-4 June 2006. On 14.12.2007 a second club named "Black Sea" was established in Varna. (5)

Gia Off-road $4 x 4$ Club was founded by passionate fans of Off-road Automotive Sports in 2010. Since the beginning of 2011, the club has been officially licensed to BFAS. The main task is to promote this extreme sport by organizing competitions, walks, free trainings and courses and providing up-to-date information from the adrenaline world. In their fairly short history, the off-road club team with Veselin Radev and Atanas Georgiev and Mitsubishi Pajero have had 4 performances in 2010: "Opening of the season 2010" - Tryavna, "Rally trophies 2010" - Varna, Baha Bulgaria 2010" - Dupnitsa and Balkan Off-road Marathon - Bulgaria and Greece, where they won 2nd place in the Adventure class. "Geo off-road 4x4" Club organized the first off-road competition for Burgas, which took place on the town's fest day on 05.12.2010. After the successful presentation, it was decided that "Burgas Off-road 2010" would become an annual tradition. (6)

The Bulgaria Trophy Challenge is part of the National off-road championship for off-road vehicles up to 3.5 tons and includes separate races with similarly difficult conditions on the territory of the Republic of Bulgaria. The competitions are held in one major class "Trophies", characterized by a relatively high degree of difficulty and extreme elements of test subjects and machines. The crews compete for the Bulgaria Trophy Challenge Cup at the end of the season. (7)

\section{AIMS AND TASKS OF THE STUDY}

The aim of the study is to present the factors and motives for taking certain actions among the participants and the observers of one of the 
most extreme sports in Bulgaria - off-road racing. To capture the trend, a comparison is made in the dynamics of the views and the given assessments in two separate years. Until now Bulgaria has made scientific and research surveys of the different elements of the offroad tourism. (7) The idea is to lay a foundation by providing information that will assist future work to solve problems in this area. The study seeks to show how the conditions of this type of entertainment and sport satisfy tourists, what preferences they have for improving and diversifying their vacation.

The following tasks have been set and implemented:

- to reveal the preconditions and conditions for the development of off-road tourism in Bulgaria;

- to reveal the financial side in organizing such events;

-clarifying the demographic and social characteristics of the visitors of the event under study.

The subject of the survey is the Bulgaria Trophy Challenge off-road race as part of the off-road national championship.

The subject of the survey is participants and visitors in the individual stages of the competitions as well as the local population living near the most popular routes and itineraries.

\section{SURVEY, MONITORING AND ANALYSIS OF THE DEVELOPMENT OF THE OFF-ROAD AND THE RELATED TO IT TYPES OF TOURISM IN BULGARIA}

The purpose of this survey is to explore attitudes among participants and observers of an off-road event.

Target group: The respondents are aged over 18 , tourists visiting Bulgaria Trophy Challenge 2014 at Plovdiv, Bulgaria Trophy Challenge 2014 at Ivanski, Shumen for the period 01.0601.08 .2014 (7) and "Bulgaria Trophy Challenge 2017" in the town of Kardzhali, "Bulgaria Trophy Challenge 2017" in Varna for the period 03.03- 07.05.2017

Number of respondents: 76 people in 2014 (7) and 61 persons in 2017.

Interview method: Directly standardized interview on the day of the event.

Questionnaire content: 27 questions, of which 26 closed and 1 open; some of the closed questions responded to more than one answer, and therefore the overall percentage of data processing exceeded $100 \%$.

\section{Survey results:}

In 2014, 100\% of all respondents were Bulgarian citizens. In 2017, $5 \%$ of the visitors were foreigners, which showed an increasing trend of activity among foreign tourists. As in 2014 , most of the visitors were between the ages of 30 and 50, employed, with secondary or tertiary education with an income of over and above BGN 1000. In 2014, the proportion of men who were interested in events of this type was predominant. $34 \%$ of the respondents were women, as there was an increase in the presence of the fair sex in such competitions. This was due to the fact that part of the organizers of the events started to initiate competitions not only for men. It turned out that the frequency of practicing extreme tourism, off-road tourism, was more than five times a year. We can conclude that this type of recreation was practiced year-round, without limitation in the season, due to the geographic characteristics of our country.

Most respondents said they had practiced this type of tourism for more than two years. This gave us the reason to assert that, even though it is quite a new sport, it has been developing at a rapid and sustained pace. Visitors believe that this way of doing sports and spending leisure time is healthier for them and strengthens their overall health status.

If in $201484.21 \%$ of respondents considered that Bulgaria had the right conditions for development of off-road tourism, in 2017 this potential is increasingly being absorbed. Positive answers are already $100 \%$, which shows that there are sufficient conditions for doing this kind of activity. They say that the country's natural assets are grace for off-road tourism. (Figure 1, Figure 2)

The main reason for practicing extreme forms of tourism is also changing. If in 2014 the highest percentage went to those in need of high adrenaline - $73.68 \%$, in 2017their percentage fell to $40.98 \%$, and the proportion of those driven by their desire to overcome fear has risen. There are also those who say that the desire for closer contact with nature is their leading need. Because the respondents gave more than one answer, their motives can be considered as complex and complementing each other. (Figure 3, Figure 4) 


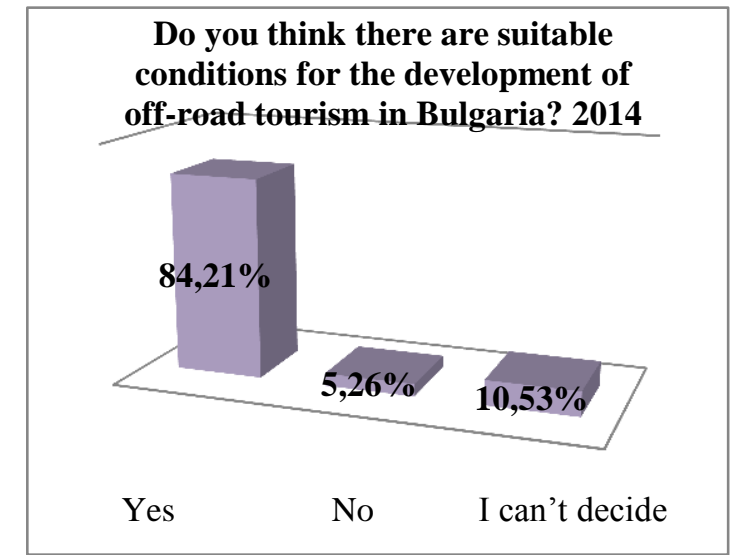

Figure 1. Conditions for the development (2014)

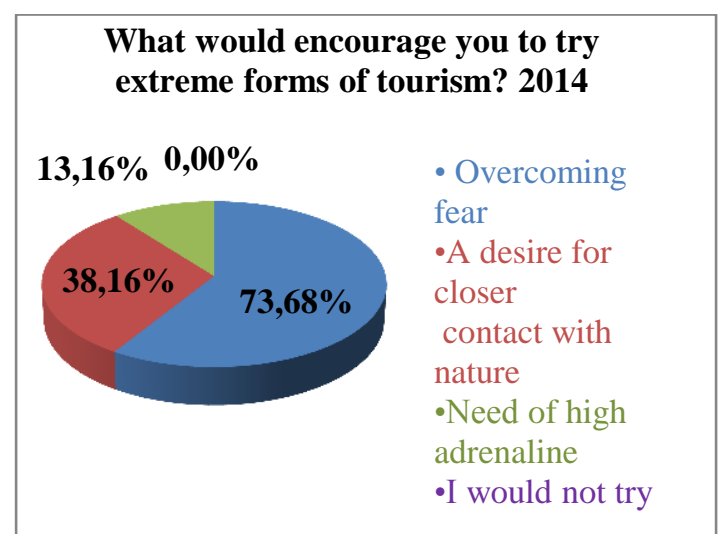

Figure 3. Motives for practicing (2014)

Regarding the influences that such events have on the participants, sustainability is marked by the feeling of increasing energy and reducing the level of stress. In practice, this can be a

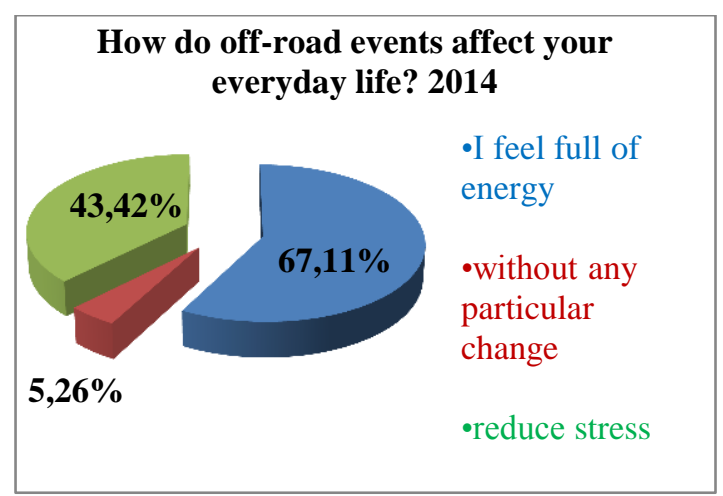

Figure 5. The influence of off-road tourism on the participants (2014)

According to the survey in 2014, $68.42 \%$ of respondents have learned about the existence of off-road tourism from friends and acquaintances, while the smaller part - from social networks and other sources. Regarding off-road advertising, the growing role of the Internet is noticeable. This can be explained by the growing importance that social networks play in our lives. There are specialized sites with free access and sufficient information on this type of activity and its accompanying events. (Figure 7, Figure 8)
ZHELEVA $V$.

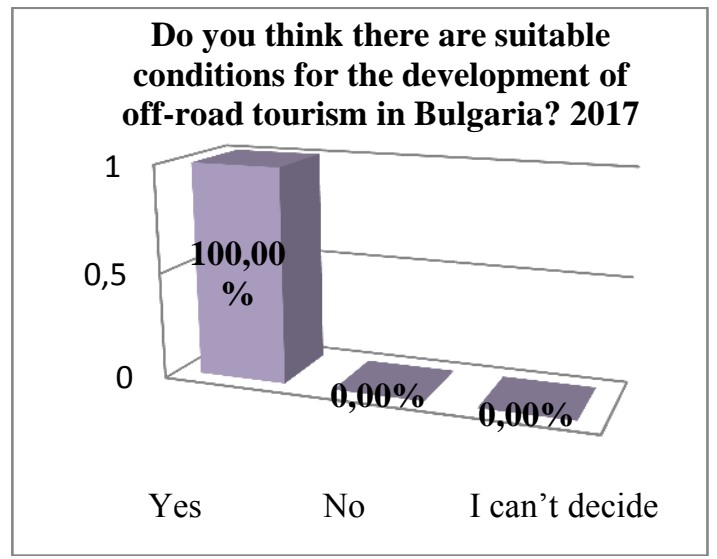

Figure 2. Conditions for the development (2017)

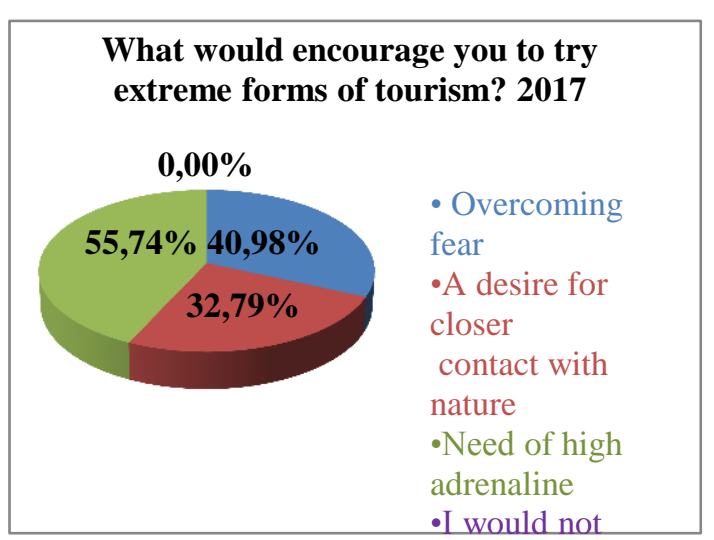

Figure 4. Motives for practicing (2017)

further factor contributing to maintenance and strengthening of the interest in extreme tourism forms. (Figure 5, Figure 6)

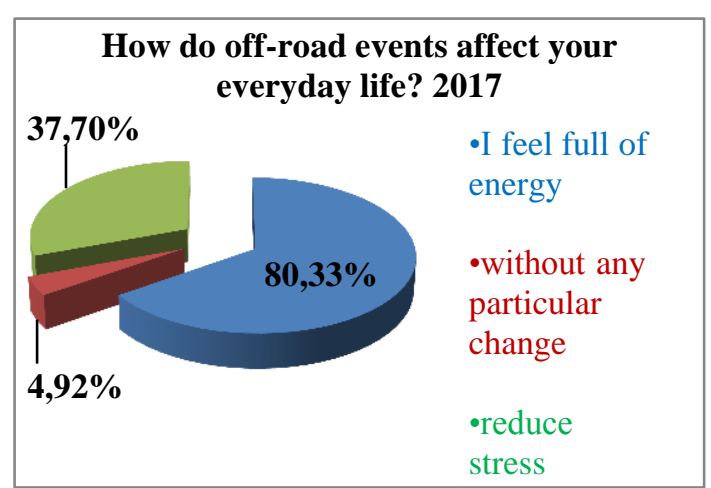

Figure 6. The influence of off-road tourism on the participants (2017)

From the graphs, it is clear that during the two examined years most tourists were rather satisfied with the product (for 2014- 59.21\%, for $2017-42.62 \%$ ). About $1 / 4$ of them believe in the professionalism of the organizers. However, there is also a percentage that shows a skeptical attitude towards this activity, which means that it is necessary for the organizers to carry out relevant surveys among visitors to improve the conditions for holding these events. (Figure 9, Figure 10) 


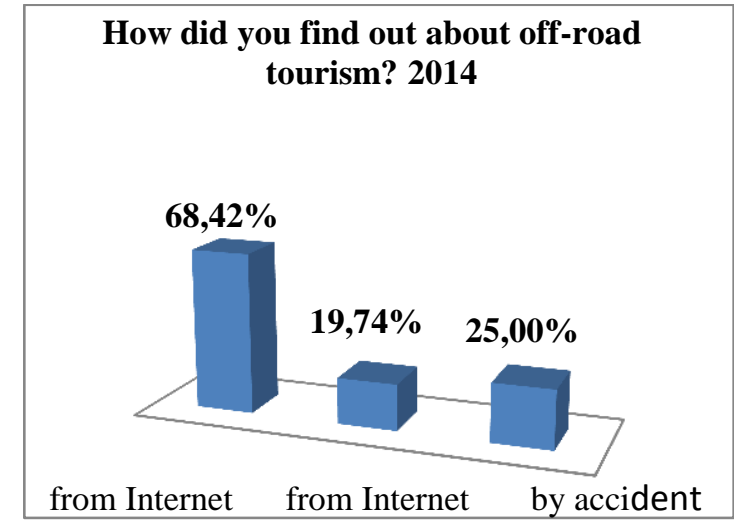

Figure 7. Awareness (2014)

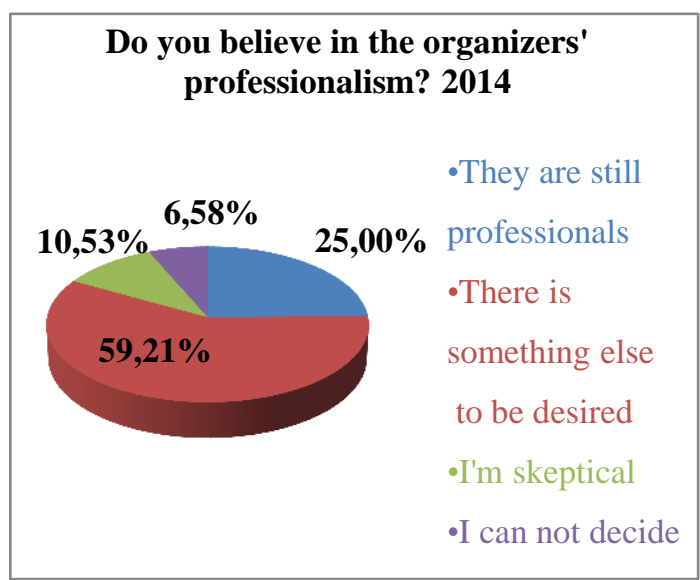

Figure 9. Organizers' professionalism (2014)

Regarding the question whether the crisis has affected this type of tourism is still the largest proportion of those who respond positively. In 2017off-road is still a very expensive pleasure. The reasons are that this type of tourism requires special equipment and the tourist services and attractions are highly

Did the crisis reflect this type of tourism? 2014

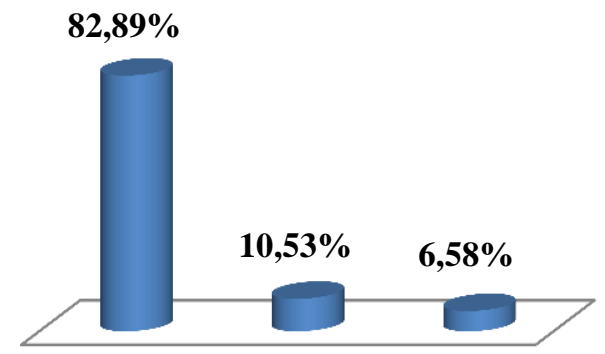

Yes, definitely No way I have no opinion

Figure 11. Crisis (2014)

It is clear from the analysis in Figures 13, 14, $\mathbf{1 5}$ and $\mathbf{1 6}$ that there is a predominant number of tourists who travel with their family (2014$47,37 \%$; 2017-42,62\%) and friends (2014- 59, $21 \%, 2017 \mathrm{~g}, 63.93 \%)$. It turns out that off-road tourism has become an event of family and friends nature. This is because a lot of tourists complete with both men and women.
How did you find out about off-road tourism? 2017

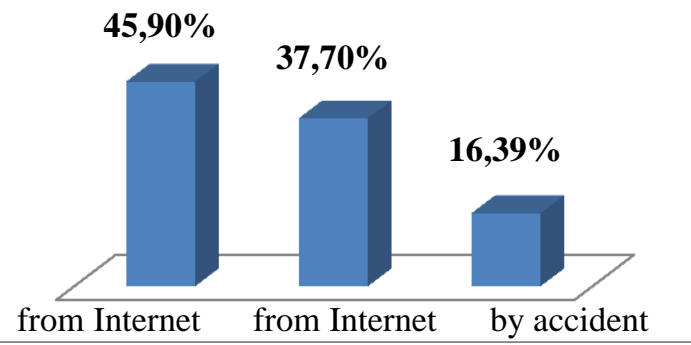

Figure 8. Awareness (2017)

Do you believe in the organizers' professionalism? 2017

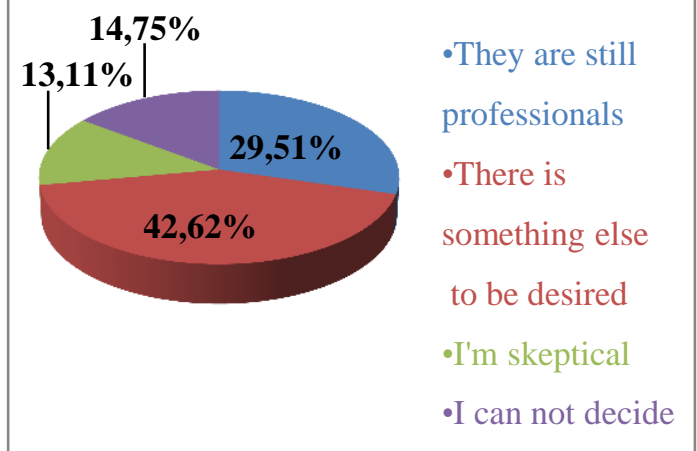

Figure 10. Organizers' professionalism (2017)

personalized, which adds more to their value. The funds invested in the maintenance of the machines and the routes have increased, which necessitates sponsorship by outsiders and companies. Most respondents say they find their sponsors through personal meetings. (Figure 11, Figure 12)

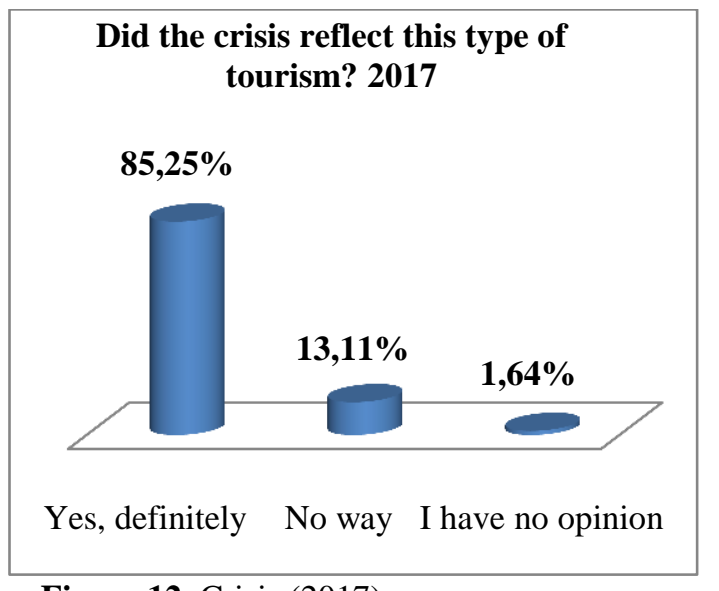

Figure 12. Crisis (2017)

In 2014, the predominant number of travelers was up to 5 people in a group, while in 2017, there was a significant increase in the percentage $(44.26 \%)$, falling to the groups of up to 10 people. (Figure 13, Figure 14, Figure 15, Figure 16) 


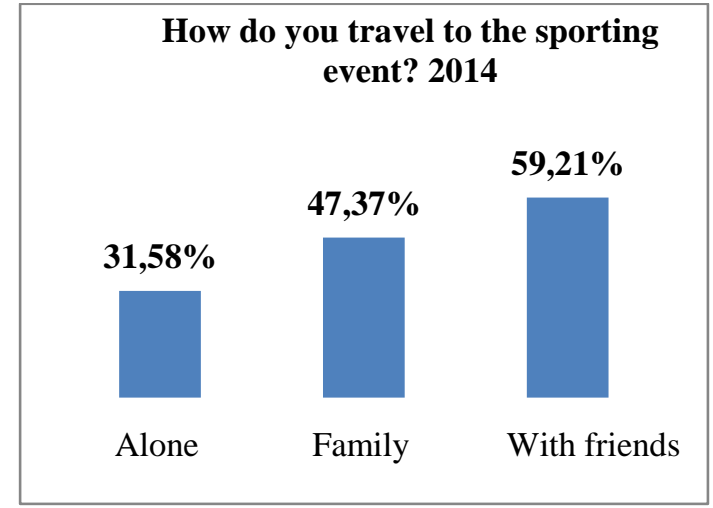

Figure 13. Travel (2014)

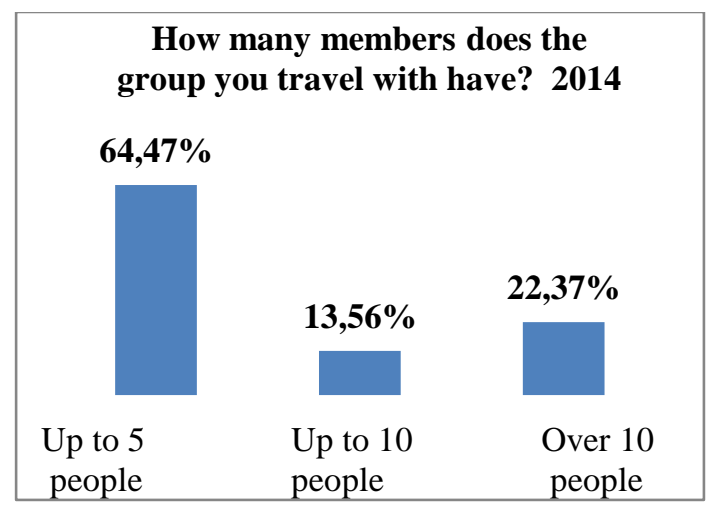

Figure 15. Travel group (2014)

\section{MAIN CONCLUSIONS}

- The geographic features of Bulgaria provide the opportunity to conduct stages of off-road events almost all year round.

- The two studies have shown that the intensive lifestyle at the beginning of the 21st century implies the development of new alternative forms of tourism (incl. Engaging in off-road races / related to relaxation, maintaining good health and restoring physical and mental balance.

- In 2017compared to 2014 (7), there is a change in the motivation to participate in such events. However, a serious problem is still the funding of such events. There is a limited amount of funds that off-road participants are willing to spend, so there is a need for sponsorship and funding from outside sources.

Recommendations

- The analysis confirms findings made in 2014 (7) that off-road races organized locally can generate economic benefits for the region, both directly and indirectly.

- The individual municipalities on whose territory the competitions are organized must take the necessary measures to include these events in the municipal development plans.

- Better advertising would ensure greater attendance.

- It is a good idea to set up promotional packages for participants, through a percentage
How do you travel to the sporting event? 2017

$63,93 \%$

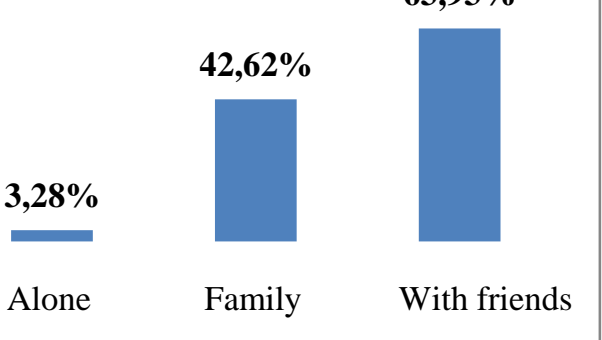

Figure 14. Travel (2017)

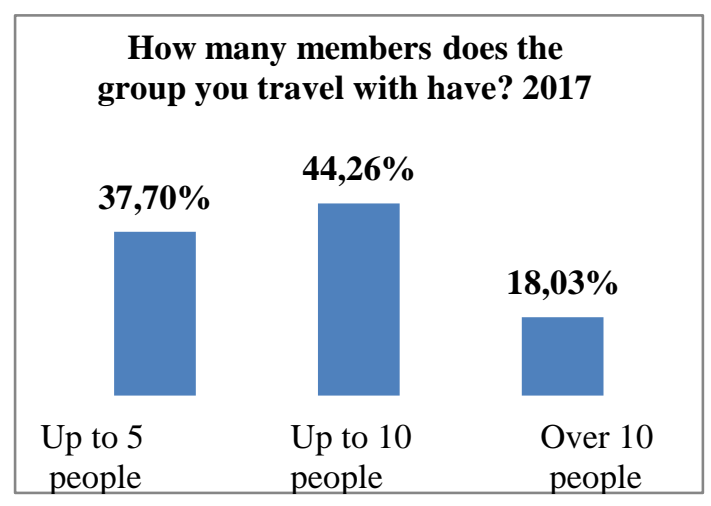

Figure 16. Travel group (2017)

reduction in fees based on a higher number of visits or combining several types of tourist services. This will increase attendance.

In conclusion, it can asserted that off-road tourism has found its place on the touristic map of Bulgaria. Young people are increasingly interested in active recreation through sport and it is good to encourage this in the future. Such an active holiday also allows for good social contacts.

\section{REFERENCES}

1. United States Forestry Service. "Willamette National Forest". (n.d.). Retrieved from http://www.fs.usda.gov/detail/willamette/recr eation/ohv/?cid=stelprdb5097794

2. Extreme sports site . (n.d.). Retrieved from http://ekstremnisportove.weebly.com/

3. Official site of the Wild Earth Guardians. (n.d.).Retrieved from http://www.wildlandscpr.org

4. Official site of Adventure Bulgaria $4 \times 4$ offroad club. (n.d.). Retrieved from http://www.4x4bg.com/

5. Official site of the Black Sea off-road club . (n.d.). Retrieved from http://www.4x4varna.com/

6. Official site of the "Geo off-road $4 \times 4$ " club. (n.d.). Retrieved from http://www.off-roadgea.com/za-nas/

7. Jeleva, V. (2014). Development of Extreme Tourism in Bulgaria (on the example of the Bulgaria Trophy Challenge 2014), diploma thesis, protected 2014 . Faculty of Economics, Trakia University. 
